Meaningful informed consent with young children: Looking forward through an interactive narrative approach

\begin{abstract}
Ideas about ethical research with young children are evolving at a rapid rate. Not only can young children participate in the informed consent process, but researchers now also recognize that the process must be meaningful for them. As part of a larger study, this article reviews children's rights and informed consent literature as the foundation for the development of a new conceptual model of meaningful early childhood informed consent. Based on this model, an 'interactive narrative' approach is presented as a means to inform 3-8 year old children about what their participation might involve, and assist them to understand and respond as research participants. For use with small groups, this narrative approach involves a storybook based on factual images related to the research project that is delivered via (re)telling. The narrative approach to informed consent is unique in its holistic design which addresses the specific needs of young children.
\end{abstract}

149 words 
Over two decades ago Hughes and Helling (1991) identified many of the same problems that today's researchers face when seeking to engage children between 3 and 8 years of age in the informed consent process, with the main challenge being that young children "may not be able to understand the research process and be truly informed" (Hughes \& Helling, 1991, p. 228). These authors explained that even though the same ethical standards apply equally to both young child participants and their adult counterparts, "children's limited experiences and developmental level make it difficult for them to understand long-term goals of research, the concept of risk, and the meaning of self-determination", with the "notions of voluntary consent and freedom to withdraw" being equally difficult (p. 227).

Since Hughes and Helling's formative work in 1991, research with young children and ideas about their role in the consent process have undergone a significant ideological shift in which “children's voices have become the catalyst for engagement" (Palaiologou, 2012, p. 1). The rights of the child movement now advocates for young children to be valued for who they are, rather than who they will become (A. B. Smith, 2011), and to be ethically and respectfully involved in research as active contributors in their own right (Kirk, 2007). This paradigm shift, which has evolved alongside our modern concept of 'childhood', encourages researchers to embrace participatory research methods.

It is important to highlight that the informed consent process has two separate parts: 'informing' and 'consenting'. It is only when potential participants understand their role and the purpose of the research project, and signify that consent, that the two aspects are combined to become 'informed consent'. Cocks (2006) noted that meaningful informed consent is made up of three essential components; the information provided by the researcher, the child's understanding of the research and what it means to be involved, and the child's response to the information provided.

Despite attempts to address the best interests of children in research, obtaining meaningful informed consent from young participants remains one of the key issues for researchers (Harcourt, Perry, \& Waller, 2011; Christensen \& James, 2008). Bourke and Loveridge (2013) also noted that involving young children in the informed consent process "presents particular challenges for researchers and accentuates some of the problems that are inherent in the concept of voluntary informed consent" (p. 154). The first of these challenges is how to adequately inform young potential participants, so that they have enough information to make 
an informed choice about being involved. The second lies in finding meaningful ways for young children to signify their agreement or non-agreement to participate. As established by Hughes and Helling (1991, p. 227), involving young children actively in the informed consent process has long been regarded as difficult to do well and can cause "problems for researchers of young children".

This paper provides the foundation for a larger study focusing on early childhood research ethics and explores the meaning of informed consent in the context of children's rights. We elucidate the complex challenges that face early childhood researchers and explore issues related to early childhood informed consent processes. Based on a conceptual model of meaningful early childhood informed consent, we take a forward looking stance and introduce an interactive narrative approach as a means to communicate information, and assist young children in understanding and responding to this information.

\section{Rights of the Child}

The United Nations Convention on the Rights of the Child (UNCRC) (1989) provided the basis on which to build a new, more participatory image of the child (K. Smith, 2009). This was the first legally binding international instrument to incorporate the full range of human rights for children in terms of civil, cultural, economic, political, and social rights and set a fundamental precedent by stating that basic human rights principles should now also be applied to children. The Convention's four core principles encompass the following: "nondiscrimination; devotion to the best interests of the child; the right to life, survival and development; and respect for the views of the child" (UNICEF, 2003, para. 4). Children are now legally entitled to the full range of human rights; they have the right to survival; to develop to the fullest; to protection from harmful influences, abuse and exploitation; and to participate fully in family, cultural, and social life (UNICEF, 2011). These principles contributed to a shift of thinking from children being considered "objects of adult work, to being competent, contributing social actors" (Mayall, 2000, p. 248), and provide a firm mandate for children "to consent (or not) to participate in research, as 'subjects', rather than as 'objects', of research" (Loveridge \& Cornforth, 2013, p. 460).

This subtle, yet dramatic redefinition of 'the child' was not intended to be restricted to governments, but to engage all of society, and by implication, affects ways in which research 
involving children should be conducted (UNICEF, 2011). UNCRC principles now underpin guidelines on ethical conduct in human research that universally dictate that the child's best interests should be upheld at all times.

There are four key rights relevant to involving children in research: Article 2 - Nondiscrimination, Article 3 - The best interests of the child, Article 12 - Respect for the views of the child, and Article 13 - Freedom of expression (United Nations, 1989). These rights influence all aspects of research with young children, with meaningful participation in research dependent on affording children sufficient 'space' to express their views, 'voice' where their opinions are heard, 'audience' in which more powerful others are prepared to listen, and 'influence' where action is taken on their behalf (Lundy, McEvoy, \& Byrne, 2011).

Article 12, known as the 'participation' article (Reynaert, Bouverne-De Bie, \& Vandevelde, 2009), is particularly significant to the way research is carried out, "not only for what it says, but because it recognises the child as a full human being with integrity and personality and the ability to participate freely in society" (Freeman as cited in Lundy, 2007, p. 928). In simple terms, Article 12 requires that research involving children should be conducted appropriately, and respect must be given to the child's developing capacity to be involved in decisions about participation.

Despite this, a number of potential barriers exist regarding the implementation of Article 12 with regard to young children's participation in research. According to Lundy (2007), children's participation is wholly dependent on the commitment and interest of adults. This can be shaped by scepticism of children's capacity, concern about the undermining of adult authority, reluctance to expend the effort required, and limited awareness of the existence or scope of the Article. Lundy goes on to caution against complacency, where initial good intentions soon evaporate once practical implementation becomes inconvenient. Thus, despite the real-world complexities of early childhood research, children's rights should not be regarded as merely the "gift of adults but a legal imperative which is the right of the child" (p. 931). This highlights the need, as suggested by Harcourt and Hägglund (2013, p. 297), for a "genuine partnership between researcher and child" founded in the rights afforded to children through Articles 2, 3, 12 and 13. 
Thus, as mentioned in the introduction to this paper, a significant ideological change has occurred in terms of children's rights to research participation. Early childhood literature reflects the view that no longer can young children be considered "too young to form an opinion about decisions that affect them" (Theobald, Danby, \& Ailwood, 2011, p. 19), instead they can be capable and competent authorities in their own lives (Harcourt, 2011). These ideas move away from questioning young children's participation in research, toward involving them as social actors and co-researchers (Theobald et al., 2011), where they can contribute to research planning, gathering data and disseminating findings (Gray \& Winter, 2011a). As a result there is growing interest in exploring how young children's perspectives can inform about children's lives (Swadener \& Polakow, 2011).

With this redefining of the sociology of childhood within social science research, there is a great deal of discussion about how best to translate the United Nations' (1989) rights of the child into ethical participatory research practices (Powell, Fitzgerald, Taylor, \& Graham, 2012). What is widely agreed is that young children have the right to be 'heard' and should receive the same ethical rights as their adult counterparts, albeit under the broad legal protection of adult consent (Green, 2012). The following discussion builds on children's rights principles and explores the process of informed consent in early childhood research.

\section{Informed Consent}

Given young children's status as minors, it is the legal requirement that a parent or guardian provides consent prior to their child's involvement in research. While it is common to secure permission from parents, the sole use of 'proxy' consent does not "fully meet the requirements of informed consent for young research subjects" (Hughes \& Helling, 1991, p. 226) where it is typically the "adult gatekeepers", and not the children being researched, who are consulted (Dockett, Perry, \& Kearney, 2013, p. 802). In countries that have ratified the UNCRC (1989), researchers also have non-negotiable ethical "obligations to accord children their rights" and must ensure that all children are "involved in decision-making processes on matters that concern them" (Harcourt \& Sargeant, 2011, p. 423). As a result, researchers are beginning to involve young children in the informed consent process (Kirk, 2007). By introducing this additional layer of child consent to the process, which allows young children to make decisions about their own involvement, researchers not only conform to the legal requirements of the Convention, but also demonstrate respect for child participants (Dockett 
et al., 2013). This respectful approach involves young children actively in informed consent and seeks their permission via either assent or consent. Obviously, the agreement to participate needs to be ongoing throughout the child's involvement and must include provision for children to freely withdraw their consent whenever they choose (Green, 2012).

In early childhood literature, the terms 'consent' and 'assent' are often interchanged. Some authors prefer to use the term 'assent' to indicate agreement by minors (those below the legal age to provide fully independent consent) (Hurley \& Underwood, 2002; Powell et al., 2012). Here, assent is often associated with lower levels of understanding than that of consent (Balen et al., 2006). Despite this, assent is based on the same principles as consent and is regarded as “a relational process whereby children's actions and adult responses taken together, reflect children's participation decisions" (Dockett \& Perry, 2011, p. 231). Other authors prefer to use the term 'consent' for both adults and young children to signify that children are capable of making an informed decision about research participation (Alderson $\&$ Morrow, 2004). It is thought that when the term consent is used for adults and assent is used as a less important label for the child's agreement, the power differential between adult researcher and child participant increases (Gray \& Winter, 2011b). However, by using consent equally for both adults and children, power shifts toward respecting the child's developing capacity and valuing their perspectives. Researchers may choose to employ both terms, with consent being used to describe a deliberate decision on behalf of the child, and assent being used in situations where the child demonstrates more passive acquiescence (Bourke \& Loveridge, 2013). Both terms can involve written, physical, and verbal signals of agreement or disagreement (Powell et al., 2012) and can form part of a renegotiable, ongoing process. For the purpose of this paper, the term consent will be used to describe all forms of young children's agreement to participate.

Informed consent is considered to be the basis of morally valid decision-making and hinges on universal principles of respect for individuals, mutual benefit, and justice (Faden, Beauchamp, \& King, 1986). These principles seek to ensure that a person is not treated as a "mere means" to an end, "but always as ends in themselves", with the common goal being to ensure that individuals "are not subjected to coercion, deception, or other kinds of manipulation" (Árnason, Li, \& Cong, 2011, p. 107). Further, for informed consent (or informed dissent) to be deemed valid, the participant must have made an entirely autonomous, self-determined choice (Miller, Keane, \& O'Toole, 2003). 


\section{Dilemmas of informed consent with young children}

With a delicate balance existing between providing protection and allowing autonomy, translating the informed consent process to the early childhood research context is not an easy task (Dockett et al., 2013). Difficulties range from practical implementation (for example, helping young children to understand the purpose of the research) to broad theoretical differences. For some researchers, the act of providing informed consent is nothing more than a formality, while others uphold it as an essential safeguard, with some even considering the issue of free choice as more important than the option that is chosen (Alderson \& Goodey, 1998). This, along with issues of privacy, the nature of a true volunteer, child competence, free choice, and responsibility for one's actions (Faden et al., 1986), all influence the way informed consent procedures are implemented with young children.

As participants, even young children have the right to understand the rules which govern their participation, namely; what is expected of them, that they are free to withdraw at any time, whether there are any potential risks, how the data will be used, and the nature of the potential audience (MacNaughton, Rolfe, \& Siraj-Blatchford, 2010). Although a uniform standard has not yet been established, the general approach for engaging young children in informed consent tends to be based on the model used with adults, with the language and method of delivery being simplified and adapted to suit the age and abilities of those involved; the research project might be explained to a group of children, with unfamiliar terms (such as 'research') discussed, followed by opportunities for the children to signify their consent. How well such approaches equip young children to understand what their consent actually means remains unclear, especially when it becomes "a hurried process with little emphasis placed on ascertaining whether children are being empowered to make an informed decision" or not (Harcourt \& Sargeant, 2011, p. 426). Thus, making the informed consent process meaningful for young children requires considerable skill on behalf of the researcher, an investment of time and building of trusting relationships, researcher reflexivity, and an ability to communicate with children (Harcourt \& Sargeant, 2011).

\section{Information, understanding, and response}

As mentioned earlier, meaningful informed consent is made up of three essential components; the information provided by the researcher, the child's understanding of the 
research and what it means to be involved, and the child's response to the information provided (Cocks, 2006). Even in adult informed consent, the "quality of understanding in a consent", the rights of the individual, and their need for information are often not given due consideration (Beauchamp, 2011, p. 519 ). Some of the specific issues of informed consent in relation to young children include describing how best to support young children to understand what is being explained, providing them with the right information, ensuring they are free to choose, reducing any researcher/child power imbalance, and facilitating the child's response. These issues are discussed in relation to the three components of meaningful informed consent.

The first component of informed consent is 'information'. The act of informing is often deemed sufficient for understanding, but even with adult participants, "mere disclosure is seldom evidence of an informed consent" (Beauchamp, 2011, p. 517). Thus, the way in which information is presented to young children is particularly important, as even simplified text-based information may not be easily understood and may not convey sufficient context for the child to feel comfortable participating. The child's developing "language skills and familiarity with research may partly explain difficulties in understanding" and "may create expectations that are not always fulfilled" (Ruiz-Casares \& Thompson, 2014, p. 8). Providing the appropriate amount of information is another area of contention. A delicate balance is required, as on the one hand deliberate omission of information is regarded as undermining autonomy (Blumenthal-Barby, 2013; Holm \& Ploug, 2013) and on the other, disclosure of too much information could result in information overload (Árnason et al., 2011).

'Understanding' is the second component of informed consent. If young participants do not understand the purpose of the research and what is required of them, their consent is of little value (Abramovitch, Freedman, Thoden, \& Nikolich, 1991). Issues of understanding can arise when researchers seek to 'benevolently deceive' young participants by shielding them from information that might adversely affect them. This paternalistic approach questions a child's capacity to understand, and relies instead on the trust and obedience of the child. The basic ethical premise of informing potential participants is compromised when researchers deliberately mislead children in order to facilitate their involvement, seek to protect them from what is perceived that they do not need to know or that which is perceived too difficult for children to understand (Will, 2011b). 
The third component of informed consent is 'response'. Providing space for young children to be "free to choose and act without controlling constraints imposed by others" (Faden et al., 1986, p. 8) is an area of informed consent that requires sensitivity and restraint. Wellmeaning researchers may unknowingly engage in 'choice architecture' where they might guide a potential participant's behaviour in a predictable manner by omitting or including certain information (Cohen, 2013). By influencing behaviour in this way, participants might be 'nudged' toward a particular option in much the same way as a caring parent might encourage a child towards the 'correct' choice. Nudging influences choice by "appearing trustworthy and projecting optimism" or by making the desired choice easier or more appealing for the individual (Cohen, 2013, p. 6). In the informed consent process with young children, choice architecture might occur due to tone of voice and facial expressions, or by making one choice appear more desirable than another. Even a researcher's encouragement or descriptive language that implies participation can place pressure on a child's decisionmaking (Conroy \& Harcourt, 2009).

A range of methods to present research information to children have been developed across different disciplines with varying levels of success. These have included written documents with simplified language (Sand, Eik-Nes, \& Loge, 2012), information delivered using multimedia that can incorporate both sound and visual elements (Synnot, Ryan, Prictor, Fetherstonhaugh, \& Parker, 2014), one-on-one researcher/child explanations (Flory \& Emanuel, 2004), storyboards (Kumpunen, Shipway, Taylor, Aldiss, \& Gibson, 2012), participatory visual methods (Ruiz-Casares \& Thompson, 2014), and the use of cartoon images (Dockett et al., 2013). Results have indicated that, in general, the way children relate to ethics information is dependent on culture, context, and their perception of free choice; and that the form and content of the ethics information can affect the way children respond. Further, it was found that visual representations combining images and texts can promote understanding, encourage researcher/child discussions, provide opportunities for children to practice decision-making, and additionally, that children value being consulted about research participation. These results highlight the importance of using a child-centred approach when presenting information to children.

If children are to be acknowledged as autonomous agents and capable of making an intelligent choice, then they must also be regarded as best equipped to make their own judgements (Will, 2011a). Providing young children with opportunities to make authentic 
choices about participation, requires that they signify their response in a manner that is both accessible and meaningful for them. Current strategies for obtaining consent include forms of written agreement, for example, asking the child to write their name, colouring a 'smiley face', taking the child's thumbprint (Harcourt \& Conroy, 2005), or by writing the word 'OK' (Harcourt, 2012). Other verbal and non-verbal methods for obtaining children's consent include children responding to invitations to participate by answering 'yes' or 'no', facial expressions, body language (walking away) and deliberate signals (such as thumbs up or thumbs down) (Dockett, Einarsdóttir, \& Perry, 2012). For young children, some of whom are likely to be pre-literate, the manner in which they are asked to record their consent requires special consideration. While all of these strategies are workable, it is not necessarily clear that children truly understand to what they are giving their consent. This issue can be compounded when informing and consent documents are limited in educational value, use complex language, and are not visually appealing (Wright, 2012). A transparent strategy that makes clear that children understand their choices prior to consent (or dissent) is essential.

\section{An interactive narrative approach to informing young children}

The following theoretical discussion draws together current thinking on children's rights and informed consent, and presents a forward thinking approach and conceptual framework to informing, understanding, and response with children aged $3-8$ years of age. This approach has been developed for use with a small group of children, or a single child, where time is available for relationships between the researcher and children to develop. While this approach aims to support children as co-researchers, it is acknowledged that there are research situations where adults may need to override children's refusal to participate or where children's participation as co-researchers is not appropriate.

We propose the use of a new interactive narrative approach to informed consent for young children. It aims to meet their needs during research involvement in relation to adequately informing them, supporting their understanding and gaining their meaningful consent or dissent. This narrative approach has children's rights and human ethics obligations at its foundation and embedded throughout. It seeks to engage and interest young children, and to be reflexive enough to enhance individual levels of competency. The approach is also designed to support inclusive participatory research practice, and builds on key interactions between adult and child. In order to meet these multi-layered and complex challenges for an 
holistic early childhood informed consent strategy, we have taken a narrative approach. McIntosh and Stephens (2011) endorsed the notion that narratives serve as valid meaningmaking instruments and are a successful and appropriate method for engaging children in discussion about issues that affect them. Given that narrative is already a familiar part of young children's lives, and is used effectively in other contexts to engage and inform young children, we suggest that it now be incorporated into the informed consent process.

As a basis for obtaining meaningful informed consent from young children, the narrative approach involves the use of a storybook that combines text and images that relate to the research project. The narrative is based on fact (nonfiction) and is delivered via (re)telling (interactive). This narrative tells a story about the research and is made up of two sections. The first section of the story informs the child about the research project, while the second section describes what participation would involve and how the child might signify consent or otherwise. For example, in the first section, the context of the research would be presented to allow the child to help define the research problem and to suggest what might be done to address this problem. The second part of the story would provide details of what the child's participation would involve, including how data would be collected, what might be done with it, and the potential audience for the results. The final pages of the story would provide valueneutral information about making a participation choice and signifying consent. Factual images are key to describing the research and would include photographs of people involved in the research and the research setting. The story can be delivered using computer technology or as a hard copy book. Using the former, interactive technologies such as a 'touch-screen' and sound effects can be utilised to enhance the child's engagement with the story. The reading of the story can be done individually or with small groups of children. For example, the researcher and children can engage in conversations about the story, providing opportunities for clarification. A hard copy of the storybook can be taken home for retelling with family and, depending on the context, the child's decision to participate in the research could be delayed to allow this to happen.

'Narrative nonfiction' plays a large part in this approach as it meets the needs of ethical informing. Narrative nonfiction typically follows a story format or step-by-step procedure and has the feel of a story. This type of text has "information about the real world to impart within the logical sequence of a narrative" MacDonell (2006, p. 16). MacDonell explained that even very young children are capable of constructing meaning from this type of 
informational (factual) text and that despite a wide variation in skills and ability, research indicates that young children actually enjoy and desire informational texts. In terms of supporting young potential participants in the informed consent process, the use of nonfiction picture books is particularly appropriate, as they can provide a purpose for learning, a platform from which to develop common knowledge, and a method of making abstract concepts more concrete and accessible (Schoch, 2012).

Figure 1 presents a conceptual model of the interactive narrative approach to meaningful early childhood informed consent. In this holistic model, the outer four concepts (children's rights, human ethics protocols, child's level of competence and participatory research) are considered necessary for rights-based research with young children. We are suggesting that the inside two concepts in Figure 1 (interaction and narrative) provide an innovative approach to making the informed consent process meaningful for young children.

\section{INSERT FIGURE 1 NEAR HERE}

Figure 1. Conceptual model of the interactive narrative approach to meaningful early childhood informed consent

The outer circle of this figure represents children's rights. The narrative approach supports children's rights by respecting children's developing capacity for understanding and their right to be involved in decisions that affect them. The underlying principle of engaging young children around a narrative, or storybook, of informed consent is based on a desire to uphold children's best interests (Article 3). A research story that uses both text and images appropriately supports diversity, can be adapted to meet the varying needs of children (Article 2), and is particularly suitable for pre-literate or indigenous groups whose culture is strongly story- or image-based. A narrative that has the potential to evolve along with the child's involvement by incorporating the child as a character in a 'living' informed consent story, respects the child's views (Article 12) and provides the child with a forum to express these views (Article 13).

The narrative approach has much potential to support human ethics protocols, as represented by the second circle in Figure 1. Using a child-friendly story that is based on fact and includes photographic images can provide the child with the information they need to make a meaningful decision about participation in a research project. By weaving into a storybook 
photographs of the people the child will meet, images of the research setting, ways in which the child might be involved, images of how the research may be presented to others, along with other essential information about research participation, the child receives information in a manner that is accurate, interesting, and easily understood. This approach has the potential to present abstract concepts in a respectful manner that is accessible to the child, provide a concise overview of the project (including research context and aims), and scaffold the child to understand the rules that govern their participation.

The third circle in Figure 1 represents children's level of competence. Informing young children using factual narratives respects children as capable and competent, and supports children to actively construct their own learning through play-based experiences with the story. Visual and multimodal texts have become a common component of early childhood education (Soundy \& Drucker, 2010), with the combination of narrative and images providing flexibility in delivery to support children at their individual level of understanding. Young children naturally make meaning through a combination of what they see and hear (Clark, 2011), with images serving to support good communication, promote understanding, and stimulate discussion (MacDonald, 2009). Storybooks with images enable children to learn about the real world, especially those aspects that they have not experienced directly (Woolley \& Cox, 2007). Photographic images in narrative are particularly valuable as they support oral and written explanations, add depth to the child's understanding, promote discussion of complex concepts, depict ideas that are not easily articulated (Ruiz-Casares \& Thompson, 2014), and stimulate children's visual thinking (Soundy \& Drucker, 2010). 'Playfulness' can also be incorporated when interactive digital devices with sounds and moving images are integrated into the narrative, or when puppetry or role play is used to support the meaning of the informed consent story. The incorporation of playfulness into the story can assist children to engage with 'dry' concepts, such as the rules of research participation, which might otherwise be of little interest to them. The use of a storybook can enable researchers to meet the specific requirements of young children and respect their level of competence while navigating complex ethical concepts.

Effective informing using a narrative approach can support children's meaningful participation by involving them in "talking, thinking and deciding" about aspects of research depicted in the story (Alderson, 2008, p. 79). Participatory research is represented as the fourth circle in Figure 1. The storybook supports children to become active in their 
participation from the outset, rather than becoming passive receivers of information. By engaging with a visual, participatory story, power inequality between child and adult researcher can be reduced through mutual engagement, and by providing opportunities for researchers to respond to children's questions and listen to their views (Theobald et al., 2011). The sharing of a story about the research provides opportunities for a trusting and supportive ongoing partnership to develop between researcher and child. This approach also assists in moving children toward becoming social actors and co-participants in research, and away from being viewed as merely 'objects' to be studied, by enabling young children to understand what their participation means.

The storybook approach to informed consent supports interactions between the researcher (or other adults) and child, as represented by the fifth circle in Figure 1. This can be achieved through 'sustained shared thinking', 'dialogic reading' and 'cycle telling'. Sustained shared thinking (Siraj-Blatchford \& Manni, 2008) enables the researcher and child to work together to develop ideas about participation, to clarify these ideas through open-ended questions, extend and challenge children's understanding of the concepts presented, and provide opportunities to revisit the messages depicted in the story. The use of sustained shared thinking demonstrates genuine interest and commitment on behalf of the researcher and allows a trusting relationship to develop. By sending the storybook home to be shared over again with family and friends, parents become an integral part of the informing process by helping to extend and consolidate their child's understanding, and children are supported to make connections in their understanding. Dialogic reading involves several changes in the way adults typically read stories (Flynn, 2011; Puroila, Estola, \& Syrjälä, 2012). Whitehurst (2012) described the adult's role in dialogic reading as helping the child become the teller of the story, with the adult taking the role of "listener, questioner and audience" (para. 12). MacDonell (2006) explained that learning is more likely to occur through this interactive technique, in which the details of stories are brought to life through "commenting, clapping, movement, laughing, and questioning” (p. 24). Of particular significance in using an interactive narrative approach to inform young children is that these benefits are "true of not just storybooks but informational texts as well”' (p. 24). 'Cycle telling' and retelling also supports understanding in the informed consent process by presenting the informing message many times in a range of contexts, with a range of people, in a range of ways. According to Cortazzi and Lixian (2007), cycle telling provides layered opportunities for developing metacognitive features of planning, remembering, understanding and reflecting on 
storytelling. This allows young participants to tell and retell their story with the researcher and other members of their social circle. Interactive techniques, such as dialogic reading, cycle telling and sustained shared thinking, have the potential to bring stories about research participation to life and assist the child in developing multiple layers of meaning in relation to their role in the research process.

\section{Conclusion and further research}

The changing nature of childhood and the children's rights movement now seek to include young children actively and respectfully in research. The complex nature of research involving young children and the multifaceted issues inherent in the consent process mean that it can be difficult to obtain informed consent that is meaningful to young participants in relation to information, understanding and response.

This paper has introduced an interactive narrative approach to informed consent that seeks to convey to young children factual information about research participation, in a manner that respects their capabilities, and also meets their requirements for engagement and practical accessibility. This approach is designed to provide young children with factual background information about the setting and purpose of a research project so that they can contextualise their understanding and build a mental picture of what they will be doing and why they have been asked to do it.

There are five significant innovations in using the interactive narrative approach described. First, this approach to informed consent is based on the conceptual model presented in Figure 1. Second, the research context and purpose, rules of participation and information about signifying a response are all presented together in the form of a factual narrative, supported by photographs of real people, places and events. Third, the child participant can become part of an evolving (living) informed consent story by becoming one of the characters. Fourth, interactive techniques, such as dialogic reading, cycle telling and sustained shared thinking are used to deliver the story to promote multiple layers of understanding of informed consent concepts. As a final point, potential exists for the child's understanding to be broadened and consolidated through a copy of the story that is taken home to be shared with family and friends. 
Whether or not the suggested interactive narrative has the benefits claimed must be tested empirically. Currently, we have successfully field-tested the approach and made small modifications according to the results. We are now analysing the results of a second field-test with 3- and 4-year-old children in community playgroups during 2014. This research will result in recommendations for wider use of the strategy together with generic guidelines for the development of interactive, non-fiction narratives to suit the needs of those researchers who may wish to use this approach in their own work. We believe that such an approach has the potential to address Hughes and Hellings' (1991) long standing challenge of moving young children toward understanding research goals, facilitating free choice and enabling young participants to more fully meet the requirements of meaningful informed consent.

\section{References}

Abramovitch, R., Freedman, J. L., Thoden, K., \& Nikolich, C. (1991). Children's capacity to consent to participation in psychological research: Empirical findings. Child Development, 62(5), 1100. doi: 10.1111/1467-8624.ep9112161649

Alderson, P., \& Goodey, C. (1998). Theories of consent. British Medical Journal, 317(7168), 1313-1315. doi: 10.1136/bmj.317.7168.1313

Alderson, P., \& Morrow, V. (2004). Ethics, social research and consulting with children and young people (2nd ed.). Ilford: Barnardo's.

Alderson, P. (2008). Young children's rights: Exploring beliefs, principles and practice (2nd ed.). London: Jessica Kingsley Publishers Ltd.

Árnason, V., Li, H., \& Cong, Y. (2011). Informed consent. In R. Chadwick, E. M. Meslin \& H. Ten Have (Eds.), The SAGE handbook of health care ethics (pp. 106-116). London: SAGE Publications.

Balen, R., Blyth, E., Calabretto, H., Fraser, C., Horrocks, C., \& Manby, M. (2006). Involving children in health and social research: 'Human becomings' or 'active beings'? Childhood, 13(1), 29-48. doi: 10.1177/0907568206059962

Beauchamp, T. L. (2011). Informed consent: Its history, meaning, and present challenges. Cambridge Quarterly of Healthcare Ethics, 20(4), 515-523. doi: 10.1017/S0963180111000259

Blumenthal-Barby, J. S. S. (2013). On nudging and informed consent-four key undefended premises. American Journal of Bioethics, 13(6), 31-33. doi: 10.1080/15265161.2013.781717

Bourke, R., \& Loveridge, J. (2013). Exploring informed consent and dissent through children's participation in educational research. International Journal of Research \& Method in Education, 37(2), 151-165. doi: 10.1080/1743727X.2013.817551 
Christensen, P., \& James, A. (2008). Introduction: Researching children and childhood cultures of communication. In P. Christensen \& A. James (Eds.), Research with children: Perspectives and practices (2nd ed., pp. 1-9). Hoboken: Taylor \& Francis.

Clark, A. (2011). Breaking methodological boundaries? Exploring visual, participatory methods with adults and young children. European Early Childhood Education Research Journal, 19(3), 321-330. doi: 10.1080/1350293x.2011.597964

Cocks, A. J. (2006). The ethical maze: Finding an inclusive path towards gaining children's agreement to research participation. Childhood, 13(2), 247-266. doi: $10.1177 / 0907568206062942$

Cohen, S. (2013). Nudging and informed consent. American Journal of Bioethics, 13(6), 3 11. doi: $10.1080 / 15265161.2013 .781704$

Conroy, H., \& Harcourt, D. (2009). Informed agreement to participate: Beginning the partnership with children in research. Early Child Development and Care, 179(2), 157-165. doi: 10.1080/03004430802666973

Cortazzi, M., \& Lixian, J. (2007). Narrative learning, EAL and metacognitive development. Early Child Development \& Care, 177(6/7), 645-660. doi: 10.1080/03004430701379074

Dockett, S., \& Perry, B. (2011). Researching with young children: Seeking assent. Child Indicators Research, 4(2), 231-247. doi: 10.1007/s12187-010-9084-0

Dockett, S., Einarsdóttir, J., \& Perry, B. (2012). Young children's decisions about research participation: Opting out. International Journal of Early Years Education, 20(3), 244256. doi: 10.1080/09669760.2012.715405

Dockett, S., Perry, B., \& Kearney, E. (2013). Promoting children's informed assent in research participation. International Journal of Qualitative Studies in Education (QSE), 26(7), 802-828. doi: 10.1080/09518398.2012.666289

Faden, R. R., Beauchamp, T. L., \& King, N. M. P. (1986). A history and theory of informed consent. New York: Oxford University Press.

Flory, J., \& Emanuel, E. (2004). Interventions to improve research participants' understanding in informed consent for research: A systematic review. Journal of the American Medical Association, 292(13), 1593-1601. doi: 10.1001/jama.292.13.1593

Flynn, K. S. (2011). Developing children's oral language skills through dialogic reading. Teaching Exceptional Children, 44(2), 8-16.

Gray, C., \& Winter, E. (2011a). Hearing voices: Participatory research with preschool children with and without disabilities. European Early Childhood Education Research Journal, 19(3), 309-320. doi: 10.1080/1350293x.2011.597963

Gray, C., \& Winter, E. (2011b). The ethics of participatory research involving young children with special needs. In D. Harcourt, B. Perry \& T. Waller (Eds.), Researching young children's perspectives: Debating the ethics and dilemmas of educational research with children (1st ed., pp. 26-37). Hoboken: Routledge. 
Green, D. (2012). Involving young children in research. In I. Palaiologou (Ed.), Ethical practice in early childhood (pp. 15-31). London: SAGE Publications.

Harcourt, D., \& Conroy, H. (2005). Informed assent: Ethics and processes when researching with young children. Early Child Development \& Care, 175(6), 567-577. doi: 10.1080/03004430500131353

Harcourt, D. (2011). A phased approach to researching with young children: Lessons from singapore and beyond. Early Education \& Development, 22(5), 818-838. doi: $10.1080 / 10409289.2011 .596462$

Harcourt, D., \& Sargeant, J. (2011). The challenges of conducting ethical research with children. Education Inquiry, 2(3), 421-436. doi: 10.3402/edui.v2i3.21992

Harcourt, D. (2012). Children's rights learning book. Mt Victoria NSW: Pademelon Press.

Harcourt, D., \& Hägglund, S. (2013). Turning the UNCRC upside down: A bottom-up perspective on children's rights. International Journal of Early Years Education, 21(4), 286-299. doi: 10.1080/09669760.2013.867167

Harcourt, D., Perry, B., \& Waller, T. (Eds.). (2011). Researching young children's perspectives: Debating the ethics and dilemmas of educational research with children (1st ed.). Hoboken: Routledge.

Holm, S., \& Ploug, T. (2013). "Nudging" and informed consent revisited: Why "nudging" fails in the clinical context. American Journal of Bioethics, 13(6), 29-31. doi: $10.1080 / 15265161.2013 .781713$

Hughes, T., \& Helling, M. K. (1991). A case for obtaining informed consent from young children. Early Childhood Research Quarterly, 6(2), 225-232. doi: 10.1016/08852006(91)90009-A

Hurley, J. C., \& Underwood, M. K. (2002). Children's understanding of their research rights before and after debriefing: Informed assent, confidentiality, and stopping participation. Child Development, 73(1), 132.

Kirk, S. (2007). Methodological and ethical issues in conducting qualitative research with children and young people: A literature review. International Journal of Nursing Studies, 44(7), 1250-1260.

Kumpunen, S., Shipway, L., Taylor, R. M., Aldiss, S., \& Gibson, F. (2012). Practical approaches to seeking assent from children. Nurse Researcher, 19(2), 23-27. doi: 10.7748/nr2012.01.19.2.23.c8905

Loveridge, J., \& Cornforth, S. (2013). The ages of consent: Re-working consensual frameworks in postmodern times. International Journal of Qualitative Studies in Education, 27(4), 454-471. doi: 10.1080/09518398.2013.780316

Lundy, L. (2007). 'Voice' is not enough: Conceptualising Article 12 of the United Nations Convention on the Rights of the Child. British Educational Research Journal, 33(6), 927-942. doi: 10.1080/01411920701657033 
Lundy, L., McEvoy, L., \& Byrne, B. (2011). Working with young children as co-researchers: An approach informed by the United Nations Convention on the Rights of the Child. Early Education and Development, 22(5), 714-736. doi: $10.1080 / 10409289.2011 .596463$

MacDonald, A. (2009). Drawing stories: The power of children's drawings to communicate the lived. Australasian Journal of Early Childhood, 34(3), 40-49.

MacDonell, C. (2006). Project-based inquiry units for young children: First steps to research for grades pre-k-2. Santa Barbara: Linworth.

MacNaughton, G., Rolfe, S. A., \& Siraj-Blatchford, I. (2010). Doing early childhood research: International perspectives on theory and practice: Allen \& Unwin.

Mayall, B. (2000). The sociology of childhood in relation to children's rights. International Journal of Children's Rights, 8(3), 243-259. doi: 10.1163/15718180020494640

McIntosh, C., \& Stephens, C. (2011). A storybook method for exploring young children's views of illness causality in relation to the familial context. Early Child Development and Care, 182(1), 23-33. doi: 10.1080/03004430.2010.534161

Miller, B., Keane, C., \& O'Toole, M. (2003). Encyclopedia and dictionary of medicine, nursing, and allied health (7th ed.). Philadelphia: Saunders.

Palaiologou, I. (2012). Introduction: Towards an understanding of ethical practice in early childhood. In I. Palaiologou (Ed.), Ethical practice in early childhood. London: SAGE Publications.

Powell, M. A., Fitzgerald, R., Taylor, N. J., \& Graham, A. (2012). Ethical issues in undertaking research with children and young people. Lismore: Southern Cross University.

Puroila, A.-M., Estola, E., \& Syrjälä, L. (2012). Does santa exist? Children's everyday narratives as dynamic meeting places in a day care centre context. Early Child Development \& Care, 182(2), 191-206. doi: 10.1080/03004430.2010.549942

Reynaert, D., Bouverne-De Bie, M., \& Vandevelde, S. (2009). A review of children's rights literature since the adoption of the United Nations convention on the rights of the child. Childhood, 16(4), 518-534. doi: 10.1177/0907568209344270

Ruiz-Casares, M., \& Thompson, J. (2014). Obtaining meaningful informed consent: Preliminary results of a study to develop visual informed consent forms with children. Children's Geographies, 1-11. doi: 10.1080/14733285.2014.971713

Sand, K., Eik-Nes, N. L., \& Loge, J. H. (2012). Readability of informed consent documents (1987-2007) for clinical trials: A linguistic analysis. Journal of Empirical Research on Human Research Ethics, 7(4), 67-78. doi: 10.1525/jer.2012.7.4.67

Schoch, K. (2012). Teaching with picture books. Retrieved from http://www.squidoo.com/teachingwithpicturebooks 
Siraj-Blatchford, I., \& Manni, L. (2008). 'Would you like to tidy up now?' an analysis of adult questioning in the english foundation stage. Early Years, 28(1), 5-22. doi: $10.1080 / 09575140701842213$

Smith, A. B. (2011). Respecting children's rights and agency: Theoretical insights into ethical research procedures. In D. Harcourt, B. Perry \& T. Waller (Eds.), Researching young children's perspectives: Debating the ethics and dilemmas of educational research with children (1st ed., pp. 11-25). Hoboken: Routledge.

Smith, K. (2009). Child participation in the early years of education. Educating Young Children, 15(1), 39-41.

Soundy, C., \& Drucker, M. (2010). Picture partners: A co-creative journey into visual literacy. Early Childhood Education Journal, 37(6), 447-460. doi: 10.1007/s10643010-0374-4

Swadener, B. B., \& Polakow, V. (2011). Introduction to the special issue on children's rights and voices in research: Cross-national perspectives. Early Education \& Development, 22(5), 707-713. doi: 10.1080/10409289.2011.597028

Synnot, A., Ryan, R., Prictor, M., Fetherstonhaugh, D., \& Parker, B. (2014). Audio-visual presentation of information for informed consent for participation in clinical trials. The Cochrane Database of Systematic Reviews, 5, CD003717. doi: 10.1002/14651858.CD003717.pub3

Theobald, M., Danby, S., \& Ailwood, J. (2011). Child participation in the early years: Challenges for education. Australasian Journal of Early Childhood, 36(3), 19-26.

UNICEF. (2003). About the convention: What is the CRC? Retrieved from www.unicef.org/rightsite/237_202.htm

UNICEF. (2011). Convention on the Rights of the Child. Retrieved from www.unicef.org/crc/index 30160.html

United Nations. (1989). Convention on the Rights of the Child. Geneva: United Nations.

Whitehurst, G. J. (2012). Dialogic reading: An effective way to read to preschoolers. Retrieved from http://www.readingrockets.org/article/400/

Will, J. F. (2011a). A brief historical and theoretical perspective on patient autonomy and medical decision making: Part ii: The autonomy model. CHEST, 139(6), 1491-1497. doi: 10.1378/chest.11-0516

Will, J. F. (2011b). A brief historical and theoretical perspective on patient autonomy and medical decision making: Part i: The beneficence model. CHEST, 139(3), 669-673. doi: $10.1378 /$ chest.10-2532

Woolley, J. D., \& Cox, V. (2007). Development of beliefs about storybook reality. Developmental Science, 10(5), 681-693. doi: 10.1111/j.1467-7687.2007.00612.x

Wright, D. (2012). Redesigning informed consent tools for specific research. Technical Communication Quarterly, 21(2), 145-167. doi: 10.1080/10572252.2012.641432 


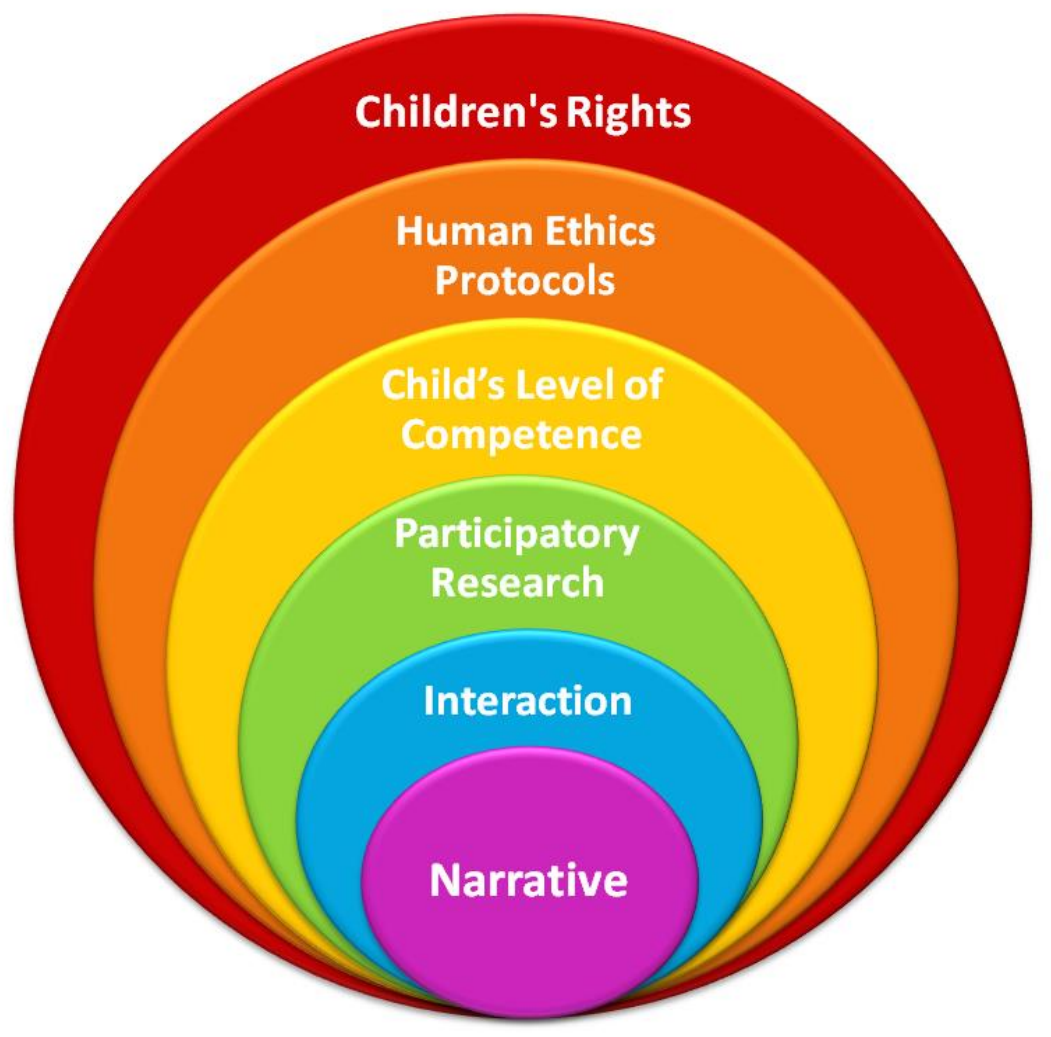

Figure 1. Conceptual model of the interactive narrative approach to meaningful early childhood informed consent 